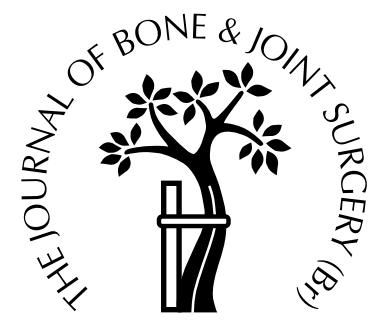

\title{
Modification of the Nicoll bone-grafting technique for nonunion of the radius and/or ulna
}

\author{
P. A. Davey, R. B. Simonis \\ From St Peter's Hospital, Chertsey, England
}

$\mathbf{W}$ e treated 19 patients with established nonunion of the radius and/or ulna by the excision of avascular bone and the grafting of blocks of corticocancellous bone from the iliac crest, augmented by rigid plate fixation under compression. This allowed early mobilisation, and bony union was achieved between three and $\mathbf{2 4}$ months after operation in all but one of the patients. The single failure was attributed to the excessive length of the defect $(100 \mathrm{~mm})$ and inadequate fixation.

J Bone Joint Surg [Br] 2002;84-B:30-3.

Received 16 October 2000; Accepted after revision 8 January 2001

Nonunion of the diaphysis of the radius or ulna produces a discrepancy in length between the two bones. The length must be restored in order to allow adequate rotation of the forearm.

In $1956 \mathrm{Nicoll}^{1}$ described a method of overcoming this problem by filling the defect left by excision of dead bone with cancellous bone from the anterior iliac crest, securing the graft by a plate and screws. In 1980 Grace and Eversman $^{2}$ modified Nicoll's technique by using a corticocancellous graft, fixed by a plate, in 18 patients with segmental defects caused by gunshot wounds or automobile accidents. Their six poor results were related to infection. Similarly, Hansis, Duffner and Weller ${ }^{3}$ successfully treated all but one of 131 pseudarthroses of the radius or ulna, but recommended this treatment only in the absence of infection. This simple technique seems to have fallen into disuse.

The use of microvascularised bone graft is an alternative solution to the problem of bone loss in the forearm. ${ }^{4}$ The fibula is the best donor site, but there is an associated morbidity.

Another possible solution is the use of a bone-transport technique and an Ilizarov circular fixator, ${ }^{5}$ but application of

P. A. Davey, FRCS Ed, Orthopaedic Specialist Registrar R. B. Simonis, FRCS Ed, Consultant Orthopaedic Surgeon Rowley Bristow Orthopaedic Unit, St Peter's Hospital, Guildford Road, Chertsey, Surrey KT16 0PZ, UK.

Correspondence should be sent to Mr R. B. Simonis.

(C)2002 British Editorial Society of Bone and Joint Surgery 0301-620X/02/111799\$2.00 the latter to the forearm is technically demanding. Both the radius and ulna are poor producers of new bone by callotasis and thus the frame may be required for many months, even when bridging a small gap. Rotation of the forearm may be very limited after successful bone transport.

We treated 19 patients with established nonunion of the radius and/or ulna, by using a slightly modified Nicoll's technique involving 'key-stoning' a block of corticocancellous graft into the defect, and securing it by a tibial plate. The placing of the cortical part of the graft opposite the plate allowed considerable compression without crushing the cancellous portion.

\section{Patients and Methods}

Between 1982 and 1998 we treated 19 patients with nonunion of the radius, the ulna or both, with associated loss of bone length (Fig. 1). Their mean age was 39 years (25 to 73) and there were four times as many men as women. The mean time from the original injury to surgery was 25 months ( 7 months to 10 years). One patient (case 11) originally had an open fracture, but there was no infection at the time of presentation. Another patient (case 2) presented with infected metalwork in situ. The plate and screws were removed and antibiotics were administered for four weeks before insertion of the bone graft. Infection, poor skin or loss of soft-tissue cover were not major problems in any patient.

Operative technique. There are two elements to the surgical technique. First, the nonunion is exposed subperiosteally and all necrotic or dubious bone and avascular scar tissue are removed. ${ }^{6}$ The marrow cavity of each fragment at the site of nonunion is opened by intramedullary drilling through the sclerotic bone. The defect is measured so that a single straight block of corticocancellous bone of correct length can be harvested from the iliac crest.

At the donor site the iliac wing is stripped of muscle and periosteum anteriorly. The crest is elevated on a hinge of posterior periosteum to expose cancellous bone. The posterior periosteum with its muscle attachment is stripped from the iliac wing, so that a straight length of corticocancellous graft, slightly longer than the defect in the forearm, may be removed. The bone block is mainly cancellous but one strong cortical bone surface is retained. 


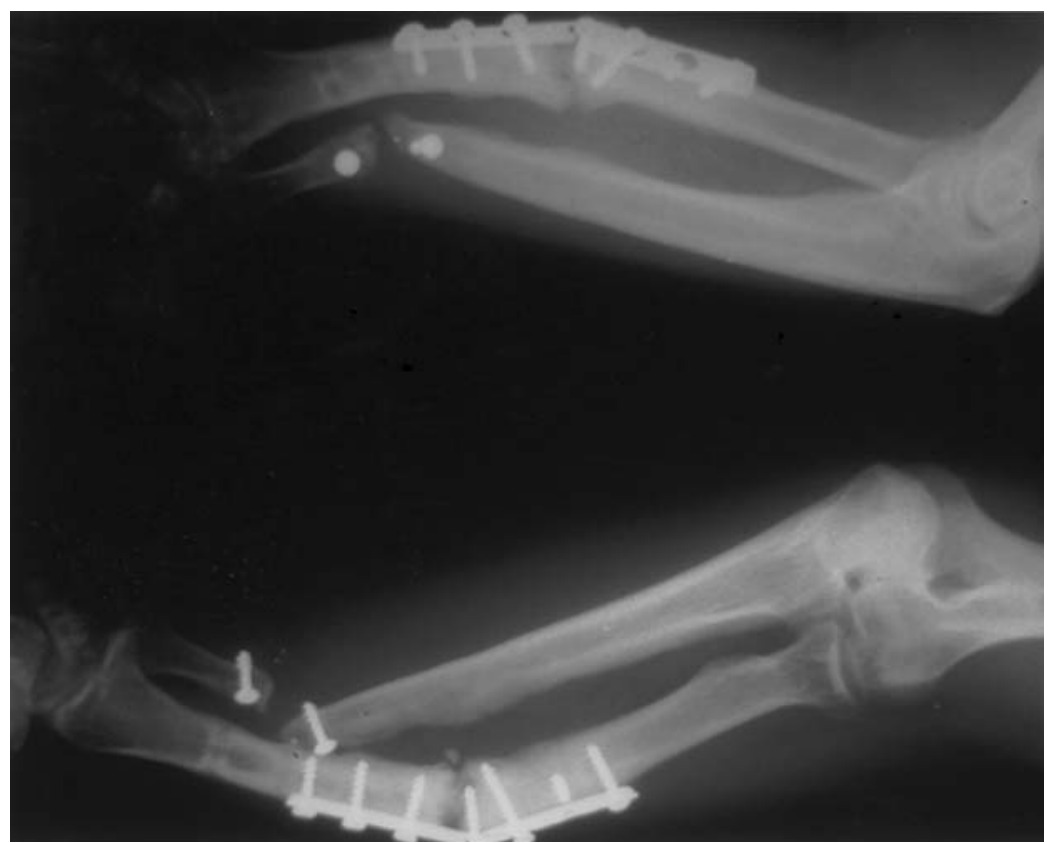

Fig. 1

Case 12. Radiographs showing severe deformity in a 39-year-old man with nonunion of the radius and ulna. He had previously undergone four unsuccessful operations for plating.

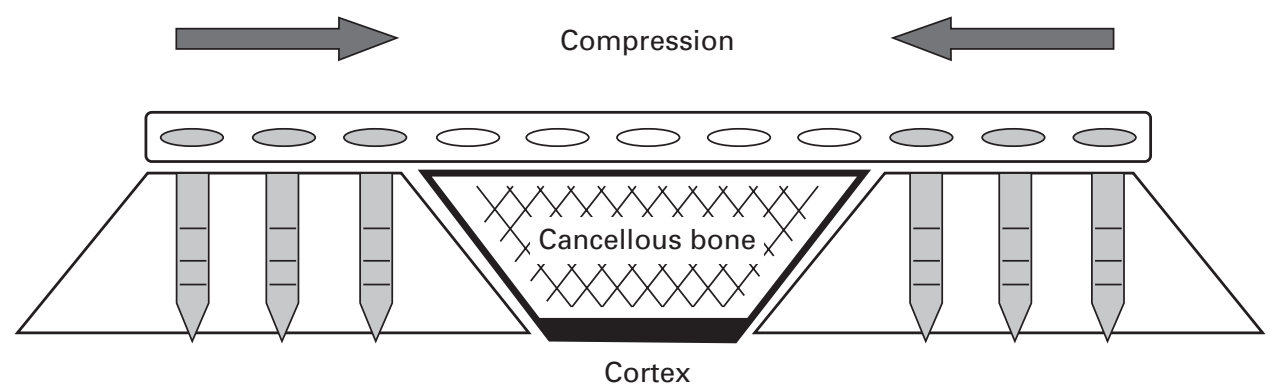

Fig. 2

Diagram showing the modified Nicoll technique in which the chamfered bone graft is compressed between the cut ends of the bone by the plate.

We modified Nicoll's original technique by chamfering the cut ends of the forearm bone and the bone block in order to increase the area of bony contact and to allow the graft to be wedged securely in place (Fig. 2). The defect is completely filled with bone, and over it is placed a $4.5 \mathrm{~mm}$ narrow tibial dynamic compression plate, which is long enough to secure a $6 \mathrm{~cm}$ graft, with three cortical screws on either side of the nonunion (Fig. 3a). Ideally, the graft should be left free and not screwed to the plate. The cortical surface of the graft is positioned opposite the plate to allow firm compression without crushing. If an $\mathrm{AO}$ compression device cannot be used because there is insufficient normal radius or ulna available, the eccentric holes in the plate can be used to compress the graft. However, this technique gives less rigid fixation. A small fragment or semitubular plate does not produce enough compression.
We did not immobilise the arm in a cast. We advised patients to move their arms gently and not to lift heavy weights or lever themselves up with their arms for three or four months. We reviewed the patients every two months until radiological union had occurred.

\section{Results}

Of the 19 fractures, 18 united. The mean length of the bone defect in these patients was $37 \mathrm{~mm}$ (20 to 60). We followed up all patients for 24 months after surgery. The mean time to radiological union (Fig. 3b) was 13 months (8 to 24) (Table I).

Radiographs in the anterior, posterior and two oblique planes were taken at each attendance. The fixation was strong enough to allow normal use of the arm a few weeks 


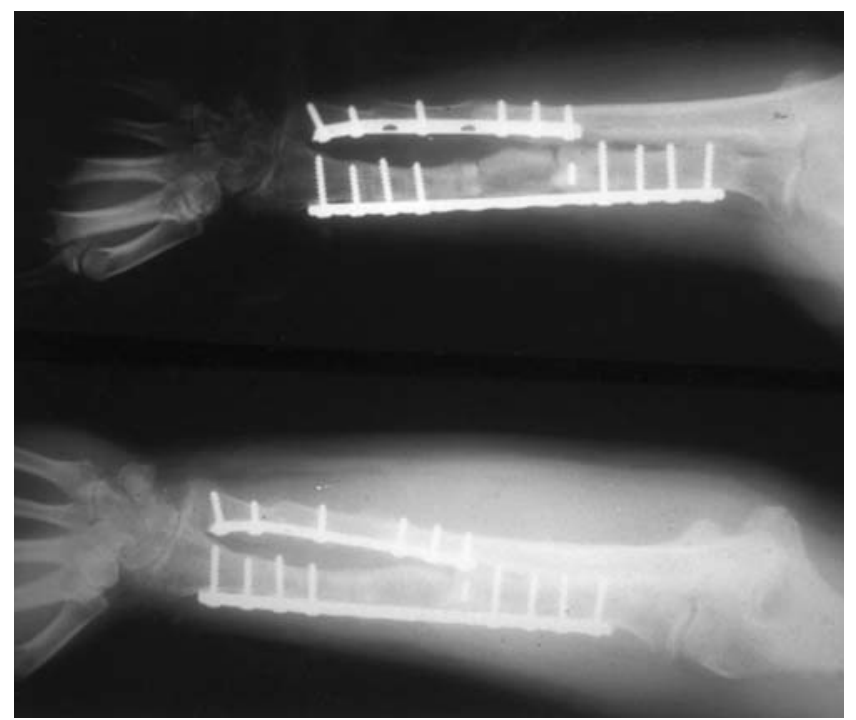

Fig. 3a

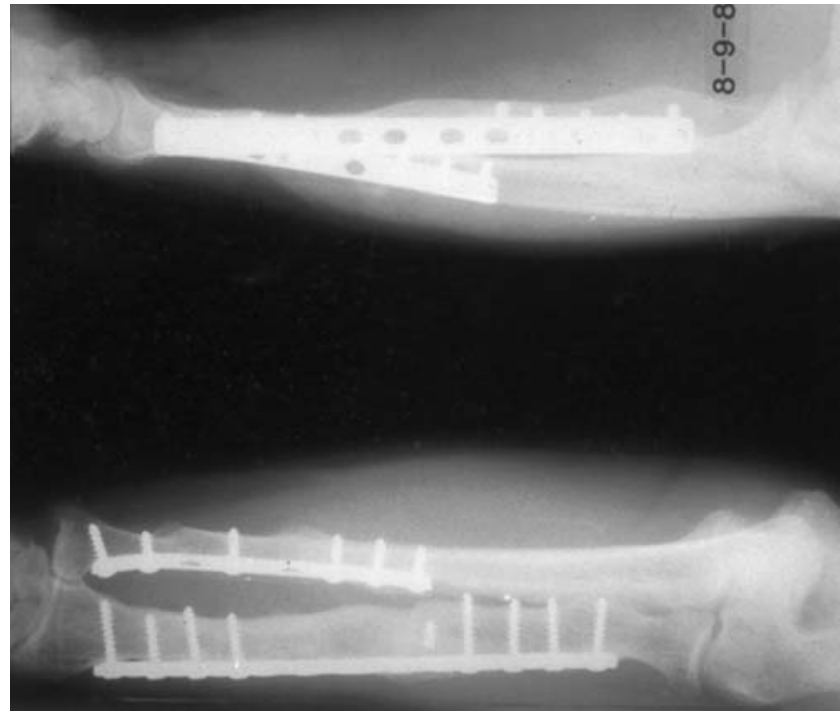

Fig. 3b

Case 12. Radiographs taken a) immediately after the Nicoll bone-grafting procedure and b) one year after operation showing consolidation of the fractures.

Table I. Details of 19 patients treated for nonunion of the radius and/or ulna by Nicoll bone grafting

\begin{tabular}{|c|c|c|c|c|c|c|c|c|c|c|c|c|c|}
\hline \multirow[b]{2}{*}{ Patient } & \multirow[b]{2}{*}{ Gender } & \multirow{2}{*}{$\begin{array}{l}\text { Age } \\
\text { (yrs) }\end{array}$} & \multirow[b]{2}{*}{ Bone* } & \multirow[b]{2}{*}{ Open? } & \multirow[b]{2}{*}{ Infect } & \multirow[b]{2}{*}{ P. ops $\dagger$} & \multirow[b]{2}{*}{ Time to $\mathrm{Sx} \nsucc$} & \multirow[b]{2}{*}{ Gap§ } & \multirow[b]{2}{*}{ Union】 } & \multicolumn{4}{|c|}{ Range of movement } \\
\hline & & & & & & & & & & Extn & Pron & Supin & Add \\
\hline 1 & $\mathrm{M}$ & 30 & $\mathrm{R}$ & No & No & 3 & 30 & 50 & 17 & Full & Full & Full & \\
\hline 2 & $\mathrm{M}$ & 31 & $\mathrm{R}$ & No & Yes & 2 & 9 & 50 & 8 & -20 & $3 / 4$ & $3 / 5$ & rop \\
\hline 3 & $\mathrm{M}$ & 35 & $\mathrm{R}$ & No & No & 2 & 120 & 50 & 12 & -10 & $3 / 4$ & $3 / 4$ & \\
\hline 4 & M & 55 & $\mathrm{U}$ & No & No & 1 & 12 & 50 & 8 & Full & Full & Full & \\
\hline 5 & $\mathrm{M}$ & 39 & $\mathrm{U}$ & No & No & 3 & 7 & 50 & 14 & Full & Full & $3 / 4$ & \\
\hline 6 & $\mathrm{~F}$ & 38 & $\mathrm{U}$ & No & No & 1 & 8 & 40 & 13 & -5 & $3 / 4$ & $3 / 4$ & \\
\hline 7 & $\mathrm{M}$ & 32 & $\mathrm{U}$ & No & No & 1 & 12 & 20 & 19 & -5 & $3 / 4$ & $3 / 4$ & \\
\hline 8 & M & 49 & $\mathrm{R}$ & No & No & 1 & 12 & 25 & 5 & Full & Full & Full & \\
\hline 9 & $\mathrm{M}$ & 25 & $\mathrm{R}+\mathrm{U}$ & No & No & 4 & 41 & U30/R60 & 24 & -25 & $1 / 2$ & $3 / 4$ & \\
\hline 10 & $\mathrm{M}$ & 29 & $\mathrm{U}$ & No & No & 2 & 12 & 25 & 19 & Full & Full & Full & \\
\hline 11 & $\mathrm{M}$ & 25 & $\mathrm{R}$ & Yes & No & 1 & 42 & 55 & 24 & Full & $3 / 4$ & $3 / 4$ & bg \\
\hline 12 & M & 39 & $\mathrm{R}+\mathrm{U}$ & No & No & 4 & 10 & U25/R30 & 14 & -15 & $1 / 2$ & $3 / 4$ & \\
\hline 13 & $\mathrm{~F}$ & 52 & $\mathrm{U}$ & No & No & 2 & 10 & 25 & 14 & Full & $3 / 4$ & Full & \\
\hline 14 & $\mathrm{~F}$ & 68 & $\mathrm{R}+\mathrm{U}$ & No & No & 2 & 60 & $\mathrm{U} 35 / \mathrm{R} 20$ & 14 & -15 & $3 / 4$ & $3 / 4$ & \\
\hline 15 & $\mathrm{~F}$ & 19 & $\mathrm{U}$ & No & No & 2 & 20 & 100 & N/U & -5 & $3 / 4$ & $3 / 4$ & vfg \\
\hline 16 & $\mathrm{~F}$ & 56 & $\mathrm{U}$ & No & No & 1 & 50 & 20 & 6 & -10 & $3 / 4$ & $3 / 4$ & \\
\hline 17 & $\mathrm{M}$ & 29 & $\mathrm{U}$ & No & No & 1 & 50 & 30 & 8 & Full & Full & Full & \\
\hline 18 & $\mathrm{~F}$ & 56 & $\mathrm{U}$ & No & No & 2 & 50 & 35 & 10 & -5 & Full & Full & \\
\hline 19 & M & 33 & $\mathrm{U}$ & No & No & 3 & 78 & 35 & 12 & Full & Full & Full & \\
\hline
\end{tabular}

* $\mathrm{R}$, radius, $\mathrm{U}$, ulna

$\dagger$ P. Ops, previous operations

$\$$ time from original injury to surgery (months)

$\S$ bony defect $(\mathrm{mm})$

II time to union after Nicoll bone grafting (months)

II two years after Nicoll bone grafting. Flexion was full in all cases. Add, additional surgery; rop, removal of plate and antibiotic treatment four weeks before Nicoll bone grafting; bg, Phemister bone graft; vfg, vascularised fibular graft

after surgery, but lifting heavy weights was avoided for three or four months.

At 24 months all patients had full flexion of the elbow (Table I) although 50\% lacked some extension and rotation of the forearm. All had a better range of movement than before surgery; even those who had been injured three to ten years before surgery and who had undergone several previous operations achieved a range of pronation and supination which was at least $50 \%$ of normal.
Two patients required additional treatment. One (case 2) who had infected metalwork at presentation received antibiotics for two weeks after the bone-grafting procedure. We augmented the fixation in one patient (case 11), who originally had a compound fracture, with additional Phemister cancellous bone graft when there was no evidence of union at 14 months. The fracture went on to solid bony union ten months later.

The single patient with a fracture which did not unite 
(case 15) had a $100 \mathrm{~mm}$ defect in the radius after a motorcycle accident. We were unable to obtain sufficient length of straight graft and used two pieces of corticocancellous bone to bridge the gap. We considered both fixation and compression to be inadequate. After 15 months the graft and plate were replaced by a vascularised fibular graft, and union was achieved seven months later, with good function and an excellent range of movement.

\section{Discussion}

Nonunion of the bones of the forearm occurs when inadequate fixation leads to movement and abrasion at the site of the fracture, resulting in bone loss.

Even after resection of the avascular bone, few of our patients had a bony gap which was more than $50 \mathrm{~mm}$. Periosteal stripping, severe comminution and avascularity caused by a high-velocity motor-cycle accident caused a long defect in both radius and ulna in one patient (case 15). The Nicoll bone grafting technique is less successful in treating long defects for two reasons. First, it depends on the compression of a straight piece of bone graft. The longest piece of straight graft which we were able to obtain from the iliac crest was $60 \mathrm{~mm}$. When pieces are longer than this, the ends tend to curve, making it difficult to obtain adequate compression. Secondly, there is a high rate of complications if there is chronic infection at the site of the fracture. The success of this technique depends on the consolidation of the corticocancellous bone graft. Some osteogenic cells may survive transportation and contribute to the formation of new bone. ${ }^{7}$ However, resorption and replacement, known as creeping substitution, are mainly responsible for the incorporation of the graft. $^{8}$ Because of its trabecular nature, cancellous bone facilitates this process better than cortical bone. The distance over which creeping substitution can reliably occur is uncertain, since it depends on revascularisation from each end of the graft. For defects longer than $60 \mathrm{~mm}$ we recommend straight vascularised fibular grafts.
Most of our patients had sustained their injuries in falls or road-traffic accidents. Nonunion of the bones of the forearm rarely seems to be associated with major skin loss. Even the subcutaneous ulna rarely has poor soft-tissue cover, as a similar tibial injury may have. When there is infection with discharging sinuses, there is a high risk of the avascular bone block becoming infected, and in such cases we would recommend a bone-transport technique with an Ilizarov frame.

Although the Nicoll bone-grafting technique is rarely used, it remains effective 40 years after it was described. Its lack of complexity makes it suitable for use by general orthopaedic surgeons in district hospitals. Prolonged immobilisation in a cast is avoided, it requires no expensive equipment and, if the bony gap does not exceed $60 \mathrm{~mm}$ and there is no gross infection, the results are excellent.

No benefits in any form have been received or will be received from a commercial party related directly or indirectly to the subject of this article.

\section{References}

1. Nicoll EA. The treatment of gaps in long bones by cancellous insert grafts. J Bone Joint Surg [Br] 1956;38-B:70-82.

2. Grace TG, Eversman WW Jr. The management of segmental bone loss associated with forearm fractures. J Bone Joint Surg [Am] 1980;62-A:1150-5.

3. Hansis M, Duffner F, Weller S. Surgical treatment of aseptic forearm shaft pseudarthrosis. Aktuelle Traumatol 1989;19:192-5.

4. Han C, Wood MB, Bishop AT, Cooney WP. Vascularised bone transfer. J Bone Joint Surg [Am] 1992;74-Ä:1441.

5. Ilizarov GA, Kaplunov AG, Degtiarev VE, Lediaev VI. Treatment of pseudarthrosis and ununited fractures, complicated by purulent infection, by the method of compression-distraction osteosynthesis. Ortop Travmatol Protez 1972;33:10-4.

6. Weiland AJ. Current concepts review: vascularised free bone transplants. J Bone Joint Surg [Am] 1981;63-A:166-9.

7. Bohr H, Ravn HO, Werner H. The osteogenic effect of bone transplants in rabbits. J Bone Joint Surg [Br] 1968;50-B:866-73.

8. Enneking WF, Eady JL, Burchardt H. Autogenous cortical bone grafts in the reconstruction of segmental skeletal defects. J Bone Joint Surg [Am] 1980;62-A:1039-58. 